\title{
Detection of Smoke: Full-Scale Tests with Flaming and Smouldering Fires
}

\author{
OYSTEIN MELAND and LARS EINAR LONVIK \\ SINTEF NBL-Norwegian Fire Research Laboratory \\ N-7034 Trondheim \\ Norway
}

\begin{abstract}
Full-scale fire tests are carried out to study the effectiveness of the various types of smoke detectors to provide an early warning of a fire. Both optical smoke detectors and ionization smoke detectors have been used. Alarm times are related to human tenability limits for toxic effects, visibility loss and heat stress. During smouldering fires it is only the optical detectors that provide satisfactory safety. With flaming fires the ionization detectors react before the optical ones. If a fire were started by a glowing cigarette, optical detectors are generally recommended. If not, the response time with these two types of detectors are so close that it is only in extreme cases that this difference between optical and ionization detectors would be critical in saving lives.
\end{abstract}

\section{INTRODUCTION}

\subsection{Statement of the problem.}

Many fire related deaths are caused by the fire being discovered too late. This is closely associated with detector technology, in other words, how quickly detectors react to different fire developments. This is the background to the experiments described in this paper. The main objective has been to determine the differences in how such equipment detects fire and relate these results to human safety during fires in buildings.

Four different experiments were done, two experiments with smouldering fire developments and two experiments with flaming fire developments. All experiments are carried out in a room with a floor area of about $17 \mathrm{~m}^{2}$. All the fires were in bedding where the fabrics are not flame retardant. There was no other furniture in the test room apart from the bed where the fire started. The time of alarm was recorded for each detector. Measurements were also made for a number of parameters that characterize early fire developments. These are pressure, temperature, carbonmonoxide and oxygen concentrations, reduction of visibility and particle distribution in smoke as a result of the fire development. 
Results from one of each type of experiments flaming fire or smouldering fire are here reported. This results are representative.

The measurements of static pressure in the fire room concern smoke leakage through cracks, doorgaps etc, this results is not reported here. As far as particle distribution in smoke concern this was used to verify the effect of coagulation depending on the age of the smoke. This results are available but not reported.

The recorded alarm times are assessed against tenability criteria for being in the room and adjacent rooms based on the concentration of carbon-monoxide, visibility and temperature. These criteria are applied in isolation and no attempt is made to consider that multiple effects could operate simultaneously and thereby influence the critical limits. The tenability limits are based on recent research results from internationallyrecognized research bodies [8].

\subsection{Test facility - the building.}

All tests were carried out in a three storey building. These experiments were carried out in a room on the ground floor, with a floor area of about $17 \mathrm{~m}^{2}$ and a ceiling height of about $2.5 \mathrm{~m}$. The plan and a section of the test room are shown in Figure 1 . The room is connected to a corridor/staircase which is shown in the same figure.

Ventilation by infiltration was used in the test room. No mechanical ventilation system was operating. The leakage measurements and characteristics were made according to Norwegian Standard (NS-INSTA-130) $\mathrm{n}_{50}$-method.

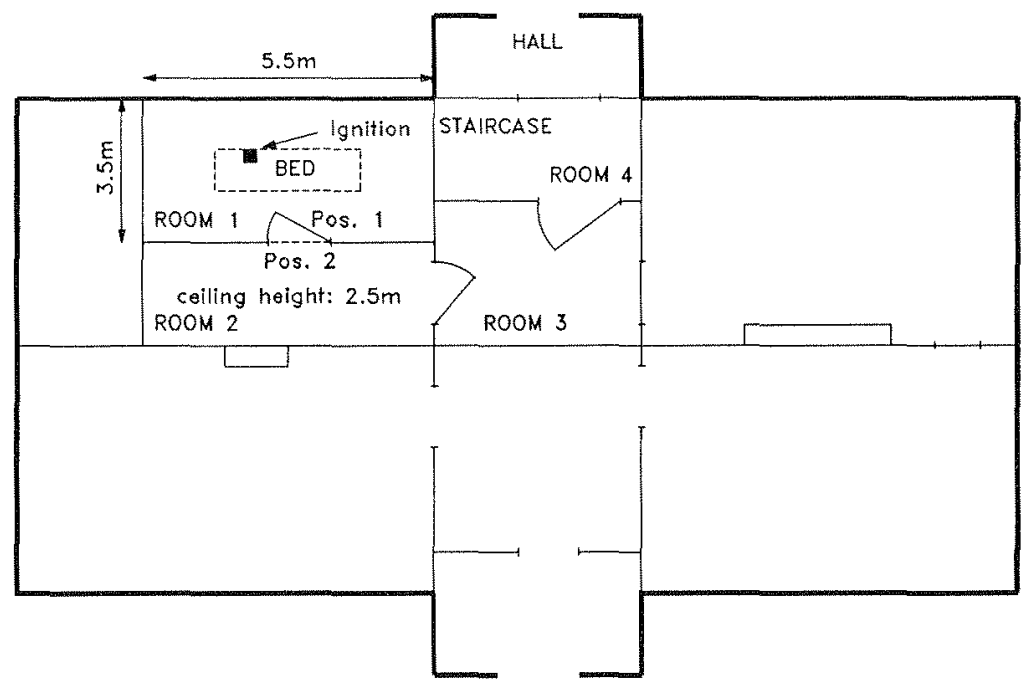

Figure 1 Test facility, plan. Pos.1 Flaming fire scenario.

Pos.2 Smouldering fire scenario. 


\subsection{Fire development.}

The flaming fire was started with an ignition source placed on a textile (the sheet).

The flaming source of ignition was: Methenamine, 1588

The calorific value was:

$4500 \mathrm{~kJ}$

The smouldering fire was started by placing a glowing cigarette on a textile (the sheet).

This method of starting a fire was chosen because of reproducibility considerations. However, both situations represent typical initial fire developments for many actual room fires.

\subsection{Fire materials.}

The same bedding was used in all experiments:

$\begin{array}{ll}\text { Mattress: } & \text { non-modified polyurethane foam }\left(35 \mathrm{~kg} / \mathrm{m}^{3}\right) \\ \text { Mattress cover: } & \text { cotton } \\ \text { Sheet: } & \text { cotton } \\ \text { Draw sheet: } & \text { cotton } \\ \text { Quilt/pillow cover: } & \text { polyester/cotton } \\ \text { Quilt/pillow filling: } & \text { polyester fibres }\end{array}$

The bedding was identical with what is used in a typical Norwegian hospital/health institution.

\section{DETECTION OF SMOKE.}

\subsection{Detectors, types and principles.}

The following equipment was used for smoke and heat detection during the experiments:

Optical smoke detector, residential type

Optical smoke detector

Ionization smoke detector, residential type

Ionization smoke detector

Smoke beam detector

Aspirating type of smoke detector

Heat detecting cable

Heat detector 
The equipment was all within the international standards of sensitivity (EN-standard, UL-standard), but not adjusted to equal sensitivity. Table 1 shows the codes, position and positions for each detector referred to in this presentation as well as the sensitivity standard. Regarding positions see Fig 2.

TABLE 1 Codes, sensitivity standard and positions for some of the detectors.

\begin{tabular}{|c|c|c|c|c|c|c|c|}
\hline \multirow{3}{*}{$\begin{array}{l}\text { Num } \\
\text { ber }\end{array}$} & \multirow[t]{3}{*}{ Type } & \multirow[t]{3}{*}{ Positions } & \multirow{3}{*}{$\begin{array}{l}\text { Stand. } \\
\text { Code: }\end{array}$} & \multicolumn{4}{|c|}{ Sensitivity (approval test fires) } \\
\hline & & & & \multicolumn{2}{|c|}{$\begin{array}{l}\text { Smouldering } \\
\text { fire }\end{array}$} & \multicolumn{2}{|c|}{ Flaming fire } \\
\hline & & & & y-val. & $\mathrm{dB} / \mathrm{m}$ & $y$-val. & $\mathrm{dB} / \mathrm{m}$ \\
\hline N5 & $\begin{array}{l}\text { Ionization smoke } \\
\text { detector, residential type }\end{array}$ & ceiling level & EN-54 & $\begin{array}{l}0.55 \\
0.86 \\
\end{array}$ & & $\begin{array}{l}0.55- \\
0.86\end{array}$ & \\
\hline A28 & Optical smoke detector & ceiling level & EN-54:9 & & 0.413 & & 0.353 \\
\hline A42 & Heat detector & $\begin{array}{l}\text { lowered } 150 \mathrm{~mm} \text { from } \\
\text { to the ceiling level. }\end{array}$ & EN-54 & \multicolumn{4}{|c|}{ (Class 1) } \\
\hline A41 & Heat detector & ceiling level & EW-54 & \multicolumn{4}{|c|}{ (Class 1) } \\
\hline A15 & $\begin{array}{l}\text { Ionization smoke } \\
\text { detector }\end{array}$ & ceiling level & EN-54:9 & 2.58 & & 0.825 & \\
\hline A.26 & Optical smoke detector & ceiling level & EN-54:9 & & 0.413 & & 0.353 \\
\hline N13 & $\begin{array}{l}\text { Ionization smoke } \\
\text { detector, residential type }\end{array}$ & ceiling level & UL-217 & $\begin{array}{l}0.55- \\
0.86\end{array}$ & & $\begin{array}{l}0.55- \\
0.86\end{array}$ & \\
\hline N15 & $\begin{array}{l}\text { Ionization smoke } \\
\text { detector, residential type }\end{array}$ & ceiling level & UL-217 & $\begin{array}{l}0.55 \\
0.86\end{array}$ & & $\begin{array}{l}0.55- \\
0.86\end{array}$ & \\
\hline N11 & $\begin{array}{l}\text { Ionization smoke } \\
\text { detector, residential type }\end{array}$ & ceiling level & UL-217 & $\begin{array}{l}0.55- \\
0.86\end{array}$ & & $\begin{array}{l}0.55- \\
0.86\end{array}$ & \\
\hline N1 & $\begin{array}{l}\text { Ionization smoke } \\
\text { detector, residential type }\end{array}$ & $\begin{array}{l}\text { lowered } 200 \mathrm{~mm} \text { from } \\
\text { the ceiling level }\end{array}$ & & $\begin{array}{l}0.55 \\
0.86\end{array}$ & & $\begin{array}{l}0.55- \\
0.86\end{array}$ & \\
\hline N2 & $\begin{array}{l}\text { Ionization smoke } \\
\text { detector, residential type }\end{array}$ & ceiling level & EN-54 & $\begin{array}{l}0.55- \\
0.86\end{array}$ & & $\begin{array}{l}0.55 \\
0.86\end{array}$ & \\
\hline A12 & $\begin{array}{l}\text { Ionization smoke } \\
\text { detector }\end{array}$ & ceiling level & EN-54:9 & 2.58 & & 0.825 & \\
\hline N4 & $\begin{array}{l}\text { Optical smoke detector, } \\
\text { residential type }\end{array}$ & ceiling level & EN-54 & & $\begin{array}{l}0.10 \\
0.16\end{array}$ & & $\begin{array}{l}0.10- \\
0.16 \\
\end{array}$ \\
\hline N3 & $\begin{array}{l}\text { Ionization smoke } \\
\text { detector, residential type }\end{array}$ & ceiling level & UL-217 & $\begin{array}{l}0.55 \\
0.86 \\
\end{array}$ & & $\begin{array}{l}0.55 \\
0.86\end{array}$ & \\
\hline N12 & $\begin{array}{l}\text { Optical smoke detector, } \\
\text { residential type }\end{array}$ & ceiling level & UL-217 & & 0.10 & & 0.10 \\
\hline A25 & Optical smoke detector & ceiling level & $\mathrm{EN}-54: 9$ & & 0.413 & & 0.353 \\
\hline N14 & $\begin{array}{l}\text { Optical smoke detector, } \\
\text { residential type }\end{array}$ & ceiling level & UL-217 & & $\begin{array}{l}0.10 \\
0.16\end{array}$ & & 0.10 \\
\hline
\end{tabular}

As far as smoke detectors of the residential type are concerned, the principles for the detection of smoke are identical to those used in the equivalent type of smoke detectors. More general; a residential type of smoke detector is an autonomous smoke detector incorporating power source and alarm buzzer, for use in private homes. 


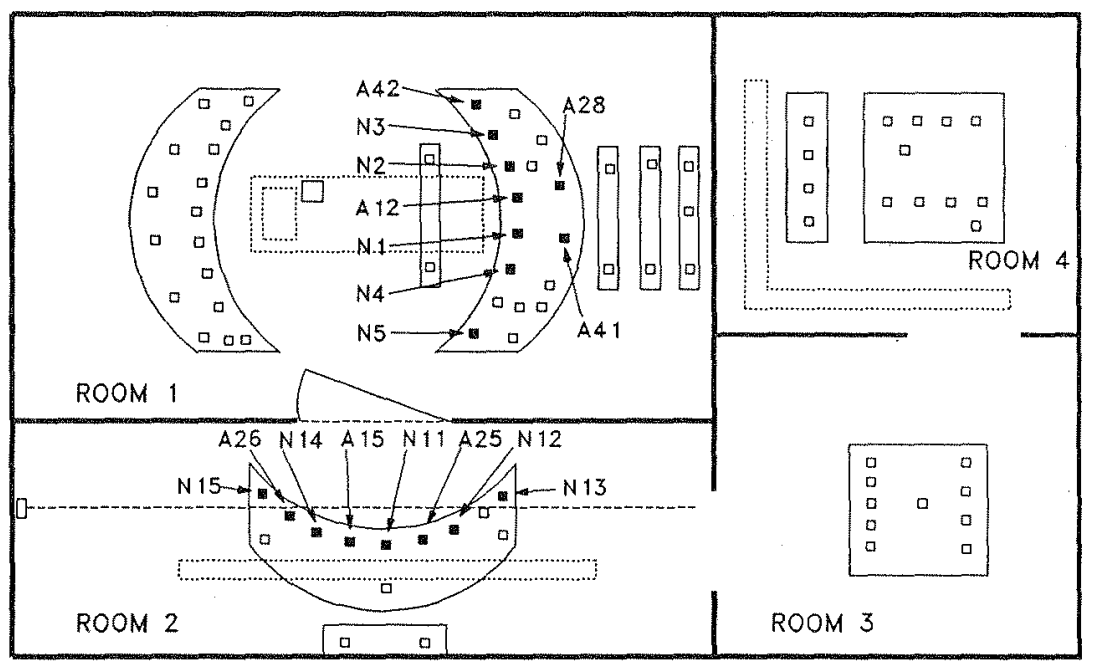

Figure 2 Detectors for heat and smoke, codes and positions. (not all of the detectors positions are referred in this paper).

Conventional type of smoke detectors is a smoke detector connected to alarm panel. Some types tested, are "on/off" types of detectors i.e. the alarm threshold are built in. Some types have an analog output that makes it possible to set the alarm threshold in the control panel.

There are two types of fire alarm systems on the market today, conventional and analog addressable systems. Conventional systems use on/off detectors i.e. information from these detectors is that they are in a state of alarm or not. If the detectors of this system is malfunctioning this will not be apparent until there is an alarm test (gas or heat applied to the sensor unit).

Analog addressable systems use detectors that transmit measurement data about the condition of the sensor unit back to the central console so that this can analyse and determine the condition of each detector. Each change will be registered so that action can be taken.

In the experiments carried out the false alarm problems is taken into account only as far as the international standards (EN-standard, UL.standard) do it.

The different detectors used in the experiments are supplied from different manufactures. Detectors from different manufactures are related to different letters, se column 1 , table 1 . 


\section{RESULTS.}

\subsection{Smouldering fires.}

In cases of smouldering fires, the critical limits for the accumulated CO-dose and visibility in the test room were reached about at the same time. This was typically 5000-6000 seconds after the start of the fire. See fig 3-4.

Both the optical smoke detectors and the residential types as well as the optical smoke detectors in the test room where the fire started detected the smoke sufficiently early to avoid a lethal situation during this type of fire development.

The ionization smoke detectors detected smoke from a smouldering fire much later than the optical detectors. When the particular conditions during the fire development are taken into consideration there are reasons to indicate that this detection principle would not provide adequate safety during this type of fire. This is in spite of the fact that the detectors were located in the test room. See fig 5-6.

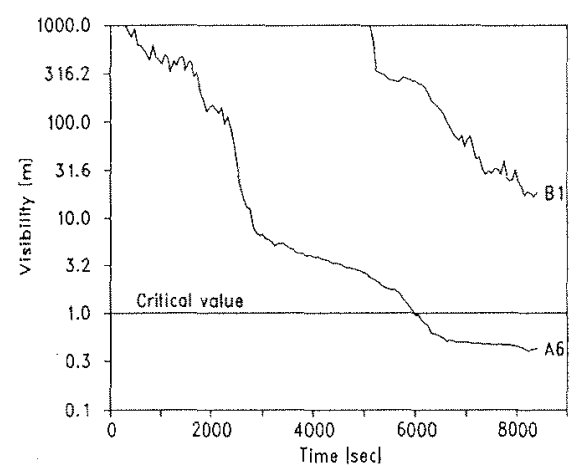

Figure 3 Smouldering fire. Reduction of the visibility at the ceiling level; position $(A 6)$ in the fire room position (B1) in the neighbouring roon. Relationship between visibility and optical density (for objects illuminated by scattered light) according to ref. [2].

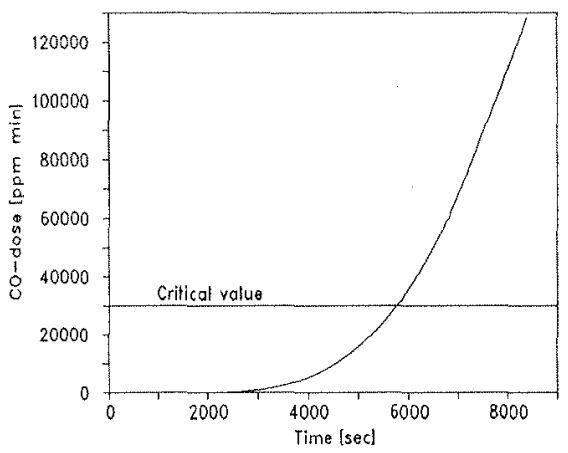

Figure 4 Smouldering fire. Dose of carbonmonoxide, ac-cumulated. According to ref [5] the threshold of $\mathrm{COHB}$ content in the blood which hinders the escape of people appears to be in the range of 30-40 $\%$, which corresponds to a $\mathrm{CO}$. dose of approximately 30000-40000 ppm min. 


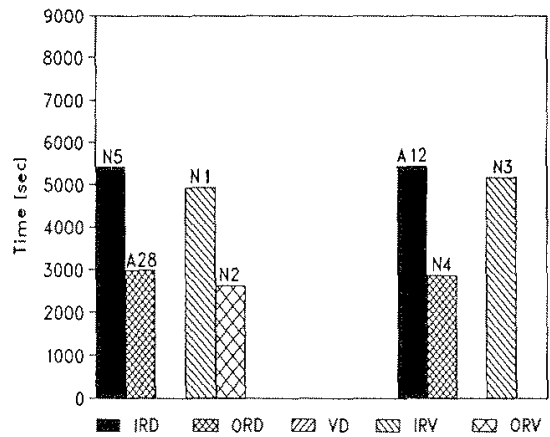

Figure 5

Smouldering fire. Times of alarm for detectors. Codes and positions, see Table 1 and Fig 2."

\subsection{Flaming fires.}

A flaming fire develops so that the critical limit is associated with the temperature in the upper smoke-filled part of the room, this is typically 200-240 seconds after ignition. The critical concentration of oxygen give critical conditions will be reached after about 300 seconds.

The ionization smoke detectors have the best characteristics for the flaming fires in the room where the fire starts. The typical times of detection for: the ionization smoke detectors and the optical smoke detectors are all under the critical limits related to heat stress [8]. According to ref [8], $150^{\circ} \mathrm{C}$ is the upper limit for the air temperature in which human individuals

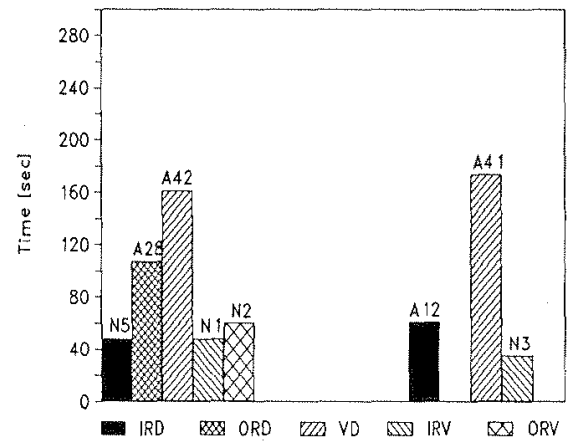

Figure 7 Flaming fire. Times of alarm for detectors. Codes and positions, see Table 1 and Fig 2." are capable of breathing. See fig. 7-8. The ionization smoke detectors give a time margin of about $160-200$ seconds in relation to the critical time limit.

Heat detectors in the test room did not provide adequate safety during flaming fires.

*) IRD: Ionization smoke detector

ORD: Optical smoke detector

VD: Heat detector
IRV: Tonization smoke detector, residential type

ORV: Optical smoke detector, residential type 
During selective surveillance (i.e. corridor mounted detectors monitors several rooms and the door to the test room is closed), both the ionization smoke detectors and the optical smoke detectors in adjacent rooms gave alarms before the situation in the room with the fire became critical. However, the evacuation time given can only be characterized as marginal.

When the door to the room with the fire is closed (see Fig. 1), cases have been reported when the sequence between the optical and the ionization-based detectors is the reverse of the situation when they are located in the fire room. In general the difference between the alarm times for the optical and the ionization detectors are reduced when detection is made from an adjacent room. This can be related to the fact that particles included in the smoke tend to coagulate (smoke ageing).

With a flaming fire and open door to the corridor the critical limit for being in the corridor associated with heat stress and reduced visibility is typically reached after 200-240 seconds (depending on the size of the corridor). See fig. 9.

The heat detector does not give acceptable safety during selective surveillance even if the door to the fire room is open.

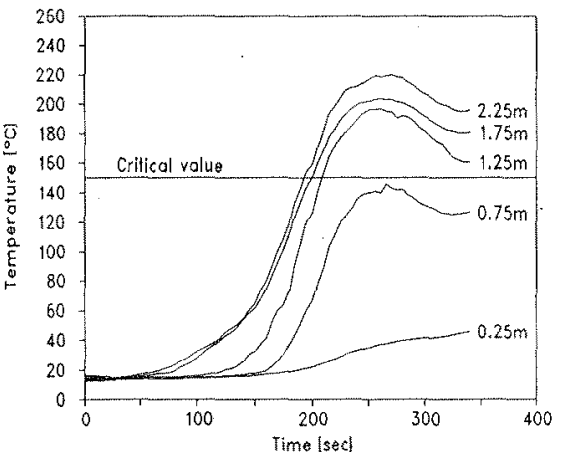

Figure 8 Flaming fire. Air temperature in the different levels of the fire room as a function of time. According to ref [1] $150^{\circ} \mathrm{C}$ is the upper limit for the air temperature in which people are capable of breathing.

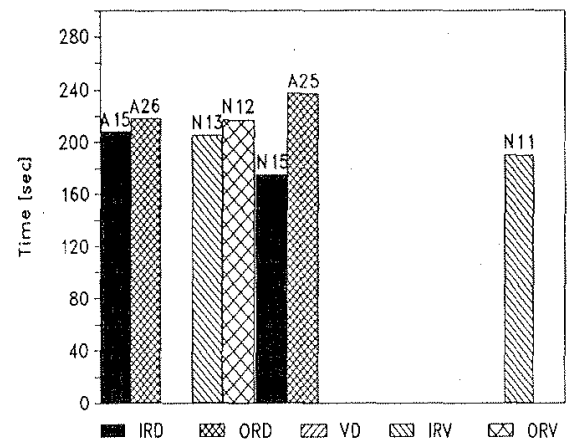

Figure 9 Flaming fire. Times of alarm for detectors. Codes and positions, see Table 1 and Fig 2."

*) IRD: Ionization smoke detector

ORD: Optical smoke detector

VD: Heat detector

IRV: Ionization smoke detector, residential type

ORV: Optical smoke detector, residential type 
For selective surveillance in homes, optical smoke detectors are generally the most safe. This is the best solution even though the safety aspect is not satisfactory if there is a long distance between the alarm and the site of the fire, (alarm in adjacent room). This situation can only be changed by careful selection of the appropriate number of such detectors in each building.

In many countries like in Norway, 90-95\% of the smoke detectors installed in homes are ionization types of detectors. Here, smouldering fires are often caused by smoking (ignition by a glowing cigarette) and those who have installed such detectors are satisfactorily safe providing measures are made to prevent smouldering fires from starting. This means that smoking in bed must be avoided. If such homes are to purchase new detectors, the recommendation is that the optical smoke detector is needed.

For individual room surveillance, such as in hospitals and hotels, optical detectors should always be used. Even though these detectors are slightly less responsive when detecting smoke from flaming fires in a room, this time margin should be related to the greater safety optical detectors provide when smouldering fires occur. The advantage of ionization smoke detectors during flaming fires is about a 15-20 second earlier warning. This margin will only be decisive for the loss of human life in extraordinary circumstances.

\section{ACKNOWLEDGEMENTS}

The authors and the staff involved in arranging these fire tests would like to thank all firms and organizations who made it possible to realize this project;

Fire Brigade of Sörum

IGP A/S

Gjensidige Forsikring

Noby A/S

Autronica A/S

Sunde A/S

The Norwegian Fire

Protection Association
- independent consulting engineers

- assurance company

- importer and distributor of residential types of detector

- Producer of smoke detectors

- importer and distributor of residential types of detector

We would also like to thank Stewart Clark, SINTEF for assistance with translating this paper into English. 


\section{REFERENCES:}

[1] Pryor, A.J.: Fullscale evaluation of the Fire Hazard of Interior Wall Finishes. South-West Research Institute, San Antonio, Texas, 1968.

[2] Drysdale, Dougal: An Introduction to Fire Dynamics. John Wiley and Sons, ISBN 0471906131.

[3] Benjamin/Clarke Associates Inc.: Smoke and Life Safety. Prepared for the Society of Plastic Industry. Aug.1983.

[4] Reinke, R.E. and Reinhardt, C.F.: Fire, Toxicity and Plastics. Modern Plastics, February 1973.

[5] Kaplan, H.L. and Hartzell, G.E.: Modelling of Toxicological Effects of Fire Gases. Journal of Fire Science, Vol.2, 1984.

[6] Fløtten, Pål: Brannfors økene ved Vesterskaun Skole sett fra deteksjonsteknisk synsvinkel, Autronica A/S, Trondheim 1989.

[7] Bryan, J.L.: Damageability of buildings, content and personnel from exposure to fire. Fire Safety Journal, 11,1986.

[8] Jan P. Stensaas, Toxicity, visibility and heat stresses of fire effluents-human tenability limits, SINTEF NBL Mai 1988, STF35 F88052 